Pesq. Vet. Bras. 36(9):831-836, setembro 2016 DOI: 10.1590/S0100-736X2016000900007

\title{
Celulite em codornas japonesas alimentadas com extrato de orégano nas dietas e inoculadas com Escherichia coli ${ }^{1}$
}

\author{
Márcia I. Sakamoto ${ }^{2 *}$, Andresa F. Esteves ${ }^{2}$, Camila A.C. Reis ${ }^{3}$, Valéria M.L. \\ Carregaro $^{3}$, Nélson L.M. Fernandes ${ }^{4}$ e Jovanir I.M. Fernandes ${ }^{5}$
}

\begin{abstract}
Sakamoto M.I., Esteves A.F., Reis C.A.C., Carregaro V.M.L., Fernandes N.L.M. \& Fernandes J.I.M. 2016. [Cellulitis in Japanese quails fed oregano extract in the diet and inoculated with Escherichia coli.] Celulite em codornas japonesas alimentadas com extrato de orégano nas dietas e inoculadas com Escherichia coli. Pesquisa Veterinária Brasileira 36(9):831-836. Departamento de Produção Animal, Universidade Camilo Castelo Branco, Av. Hilário da Silva Passos 950, Parque Universitário, Descalvado, SP 13690-950, Brazil. E-mail: mizumiss@yahoo.com.br

The aim was to evaluate the use of oregano extract in Japanese quail (Coturnix coturnix japonica) diet, challenged with Escherichia coli strains, on performance, incidence of avian cellulitis and of antibody specific antigens against E. coli. Three hundred sixty Japanese quails with 90 days of age were distributed into galvanized wire cages in a conventional shed. The experimental design was completely randomized in factorial $5 \times 2$ design (oregano extract $\mathrm{x}$ challenged or not with $E$. coli), totaling ten treatments with six replicates of six birds per cage. Oregano extract levels were $0.00,0.025,0.050,0.100$ and $0.150 \%$. Performance productive characteristics were evaluated, macroscopic lesions of cellulitis were measured after post-inoculation of the strains, and serum samples were collected for antibodies during experiment. The data were subjected to analysis of variance and averages compared by $\mathrm{T}$ test. Effect of E. coli was observed on all productive characteristics, regardless of the EO level evaluated, where challenged groups showed worse performance results. The macroscopic lesions, characteristic of cellulitis, observed only in birds of groups challenged with E. coli, were classified as mild and without bleeding. For specific antibodies, there was a higher number of birds challenged with E. coli strains in relation to unchallenged birds. It can be concluded that oregano extract supplemented in the diet was not effective against the challenge with E. coli in laying quails, and challenged birds with E. coli showed higher humoral and cellular immune response, compared with unchallenged birds, characterized by increased antibody titer and pectoral macroscopic lesion, regardless of the oregano extract levels evaluated.
\end{abstract}

INDEX TERMS: Cellulitis, Japanese quails, oregano extract, diet, Escherichia coli, antibody titer, phytotherapy.

\footnotetext{
${ }^{1}$ Recebido em 15 de outubro de 2015.

Aceito para publicação em 19 de agosto de 2016.

${ }^{2}$ Departamento de Produção Animal, Universidade Camilo Castelo Branco (Unicastelo), Av. Hilário da Silva Passos 950, Parque Universitário, Descalvado, SP 13690-950, Brasil. *Autor para correspondência: mizumiss@ yahoo.com.br

${ }^{3}$ Departamento de Medicina Veterinária, Unicastelo, Av. Hilário da Silva Passos 950, Parque Universitário, Descalvado, SP 13690-950, Brasil. E-mail: vallaracarregaro@gmail.com

${ }^{4}$ Departamento de Tecnologia em Biotecnologia, Universidade Federal do Paraná (UFPR), Campus Palotina, Rua Pioneiro 2153, Jardim Dallas, Palotina, PR 85950-000, Brasil. E-mail: nelson@ufpr.br

${ }^{5}$ Departamento de Medicina Veterinária, UFPR, Campus Palotina, Rua Pioneiro 2153, Jardim Dallas, Palotina, PR 85950-000, Brasil. E-mail: jimfernandes@ufpr.br
}

RESUMO.- Com o objetivo de avaliar a utilização do extrato de orégano nas dietas de codornas japonesas (Coturnix coturnix japonica) e desafiadas com cepas de Escherichia coli, sobre as características de desempenho, a incidência de celulite aviária e titulação de anticorpos específicos contra antígenos de $E$. coli, foram utilizadas 360 codornas japonesas, com 90 dias de idade, distribuídas em gaiolas de arame galvanizado em galpão convencional. 0 delineamento experimental foi inteiramente casualizado, em esquema fatorial $5 \times 2$ (extrato de orégano $x$ desafiado ou não com E. oli), totalizando dez tratamentos com seis repetições de seis aves por gaiola. Os níveis do extrato de orégano (EO) avaliados foram: 0,$00 ; 0,025 ; 0,050 ; 0,100$ e 0,150\%. Foram avaliadas 
características de desempenho produtivo, lesões macroscópicas da celulite após períodos pós-inoculação das cepas e amostras de soro foram colhidas para verificar a titulação de anticorpos nas aves. Os dados obtidos foram submetidos à análise de variância e as médias comparadas pelo Teste T. Foi observado efeito de $E$. coli sobre todas as características produtivas, independentemente dos níveis de EO avaliados, onde grupos desafiados apresentaram piores resultados de desempenho. As lesões macroscópicas, características da celulite, observadas somente nas aves desafiadas com E. coli foram classificadas como grau leve e sem presença de hemorragias. Para a titulação de anticorpos específicos, houve maior quantificação para aves desafiadas com as cepas de E. coli em relação às não desafiadas. Pode-se concluir que o extrato de orégano suplementado nas rações não se mostrou eficaz frente ao desafio com $E$. coli em codornas na fase de postura e as aves desafiadas com E. coli apresentaram maiores respostas imunes humoral e celular, em relação às não desafiadas, caracterizadas pelo aumento na titulação de anticorpos e pela lesão macroscópica peitoral, independentemente dos níveis de extrato de orégano avaliados.

TERMOS DE INDEXAĈ̃̃: Celulite, codornas japonesas, extrato de orégano, dietas, Escherichia coli, fitoterápico, título de anticorpos.

\section{INTRODUÇÃO}

Nos últimos anos a coturnicultura têm apresentado desenvolvimento bastante acentuado, adequando-se as novas tecnologias de produção, onde a atividade tida como de subsistência, passou a ocupar um cenário de atividade altamente tecnificada com resultados promissores aos investidores (Pastore et al. 2012).

Segundo estes mesmos autores, a coturnicultura no Brasil é uma atividade produtiva e economicamente rendável, por isso tem apresentado crescimento consistente ao longo dos últimos anos e incorporações de grandes empresas avícolas no setor. Os consumos de carnes e de ovos de codornas estão em expansão, por serem produtos de alta qualidade nutricional, saudável, sabor diferenciado e versátil na sua utilização.

Para manter a boa produtividade no mercado avícola, vários fatores devem ser considerados, como o manejo adequado, nutrição balanceada e boa sanidade. Grandes desafios sanitários podem causar prejuízos à indústria avícola, determinando perdas econômicas consideráveis (Andrade et al. 2006).

Além dos prejuízos à saúde pública, em gastos para combater as enfermidades, nos frigoríficos os processos que mais causam condenação total de carcaças são as colibaciloses, síndrome ascítica, desidratação, hepatite, má sangria e contaminação por bile e excretas. Dessas perdas, aproximadamente $19 \%$ foram atribuídas à colibacilose, podendo haver variações de acordo com o sistema de criação, manejo e sanidade da granja avícola (Borges 2006, Ferreira et al. 2012). Dentre as condenações parciais, as principais causas foram por contaminação $(46,53 \%)$, contusão/fratura $(38,66 \%)$ e celulite $(4,86 \%)$, de acordo com Borges (2006).

A celulite é uma das enfermidades que causa, principalmente, a condenação de carcaças em frangos de corte e elevada queda na produção de ovos, acarretando perdas significativas no custo da produção avícola. É caracterizada como uma inflamação purulenta, aguda e difusa do tecido subcutâneo profundo que envolve camadas celulares, havendo a formação de placas fibrino-caseosas no subcutâneo (Fallavena 2000, Andrade et al. 2006, Alves et al. 2007).

Uma das maneiras de minimizar os prejuízos causados por determinadas enfermidades seria através da alimentação, fornecendo antimicrobianos de elevada eficácia. No entanto, considerando a proibição do uso de determinados produtos na alimentação animal, em virtude de criar resistência por parte de cepas microbianas prejudiciais aos animais e de manter resíduos nos produtos destinados ao consumo humano, estudos têm sido conduzidos na busca de ingredientes alternativos que possam substituir estes antimicrobianos (Catalan et al. 2012).

Neste contexto, o extrato de orégano tem sido utilizado como alternativa na cadeia produtiva de aves e suínos em substituição aos antibióticos, e tem demonstrado eficiência no combate de bactérias patogênicas do trato gastroentérico, principalmente na prevenção às coccidioses, salmoneloses e Clostridium perfringens. É proveniente de Origanum vulgare L., família Lamiaceae, uma planta aromática caracterizada por uma notável atividade antimicrobiana e antioxidante, onde os compostos fenólicos, principalmente o carvacrol e timol, apresentaram uma capacidade de se dissolverem dentro da membrana microbiana, interagindo com mecanismos do metabolismo microbiano (Marino et al. 2001).

Diante do exposto, o objetivo deste estudo foi avaliar a utilização do extrato de orégano nas dietas de codornas japonesas (Coturnix coturnix japonica) e inoculadas, via subcutânea, com cepas de Escherichia coli, sobre o desempenho zootécnico, grau de formação de celulite aviária e titulação de anticorpos específicos contra antígenos de $E$. coli.

\section{MATERIAL E MÉTODOS}

0 experimento foi realizado no Centro Experimental da Universidade Camilo Castelo Branco, Campus de Descalvado, sob aprovação do Comitê de Ética em Uso Animal desta Instituição (CEUA/Unicastelo), protocolo no. 1-00006/2012. 0 período experimental foi de setembro a dezembro de 2014.

Foram utilizadas 360 codornas japonesas (Coturnix coturnix japonica), com 90 dias de idade, alojadas em gaiolas de arame galvanizado, com comedouro tipo calha e bebedouro nipple, em galpão convencional provido de cortinas laterais móveis. 0 programa de iluminação adotado foi de 16 horas de luz diária. Temperaturas máximas e mínimas dentro do galpão foram registradas diariamente com auxílio de termômetro de mercúrio, cujas médias durante todo o período experimental foram de $30 \pm 1,25^{\circ} \mathrm{C}$ e $25 \pm 1,95^{\circ} \mathrm{C}$, respectivamente.

0 delineamento experimental foi inteiramente casualizado em esquema fatorial $5 \times 2$ (níveis de extrato de orégano $\mathrm{x}$ inoculados ou não com E. coli), totalizando 10 tratamentos, seis repetições com seis aves por parcela. Os níveis do extrato de orégano (EO) avaliados foram: 0,00; 0,025; 0,$050 ; 0,100$ e $0,150 \%$ do EO. 
As rações experimentais foram à base de milho e farelo de soja e formuladas de acordo com as exigências nutricionais determinadas por Silva \& Costa (2009) e a composição dos alimentos, de acordo com Rostagno et al. (2011) - Quadro 1 . 0 suplemento mineral-vitamínico foi isento de qualquer substância antioxidante e antimicrobiana. 0 extrato de orégano utilizado foi proveniente de um produto comercial composto por $75 \%$ de carvacrol, $10 \%$ de timol e o restante por demais fenóis ( $\alpha$-Pinene, Camphine, $\beta$-Pinene, Sabinene, Myrecene, $\alpha$-Phellandrene, $\alpha$-Terpinene, Limonene, 1,8 Cineole, $\beta$-Ocimene, Terpinolene, 1-Octen-3-ol, Trans-Sabineme hydrate, Linalool, Cis-Sabinene hydrate, Terpinen-4-ol, $\beta$-Carvophvellene, $\alpha$-Humulen, $\alpha$-Terpineol, Borneol, $\beta$-Bisabolene, $\gamma$-Terpinene e $\rho$-Cymene).

Para as características de desempenho produtivo: a porcentagem de postura, o consumo de ração e a conversão alimentar foram avaliados a cada 21 dias do período experimental, durante 84 dias no total, onde os ovos foram anotados diariamente e as rações, pesadas no início e no final de cada período. A mortalidade foi egistrada diariamente, para o cálculo do consumo real de ração e da viabilidade final.

As aves, cujos tratamentos sofreram desafio, foram inoculadas no $5^{\circ}$ e 45으 dia do período experimental, com cepas de E. coli, isoladas pela primeira vez por Brito et al. (2003). Foi inoculada em cada ave, individualmente com agulha e seringa de insulina estéreis, pela via subcutânea, na região torácica esquerda, $0,1 \mathrm{~mL}$ de E. coli na concentração de $10^{8}$ $\mathrm{UFC} / \mathrm{mL}$. As aves dos grupos controles (sem desafio) foram inoculadas com $0,1 \mathrm{~mL}$ de tampão fosfato salina (PBS).

As mensurações macroscópicas das lesões foram realizadas após 24, 48, 72, 96 e 168 horas pós-inoculação (PI), em 18 aves por tratamento, de acordo com Peighambari et al. (1995), onde as lesões de celulite foram caracterizadas em graus: ausente (zero), leve (um), moderado (dois) a severo (três), conforme a coloração, tamanho da lesão e presença ou não de hemorragias. Para confirmar a não contaminação por outras bactérias, foi realizado o isolamento bacteriano com auxílio de swabs estéreis, colhendo material do interior da lesão. Posteriormente, os swabs foram semeados em ágar sangue e ágar Mac Conkey e cultivados durante 18 horas a $37^{\circ} \mathrm{C}$, no Laboratório de Imunologia, Microbiologia e Biotecnologia da Unicastelo.

0 método de ensaio imunoenzimático (ELISA), realizado no Laboratório de Tecnologia em Biotecnologia da UFPR/ Palotina, foi utilizado para detectar anticorpos específicos contra antígenos de E. coli, em amostras de soro de codornas, colhidos no $10^{\circ}$ dia ( 5 dias após a $1^{\underline{a}}$ inoculação), no $35^{\circ}$ ำ dia (30 dias após a 1 $1^{\mathrm{a}}$ inoculação) e no 65ํㅜ dia (20 dias após a $2^{\mathrm{a}}$ inoculação) do período experimental. Para a realização do teste ELISA, a placa foi adsorvida com o extrato antigênico de E. coli na diluição de $1000 \mathrm{ng} / 100 \mathrm{~mL} /$ cavidade, após a determinação da contração protéica pelo método de Bradford (1976). A diluição do extrato foi realizada em tampão carbonato $0,05 \mathrm{M}(\mathrm{pH} 9,6)$ e a adsorção ocorreu em refrigeração por 14 horas. Utilizaram-se placas de polietileno $\left(\mathrm{Nunc}^{\mathrm{TM}}\right)$, constituída de 96 cavidades com o fundo chato.

Para a remoção do excesso de antígeno que não se fixou na placa foi utilizado uma solução Tampão fosfato (PBS con- tendo $0,05 \%$ Tween). Para o bloqueio da placa foi utilizado solução de bloqueio (caseína 2\%; 0,05\% tween 20; diluídas em PBS), incubando-se a mesma em estufa, a $37^{\circ} \mathrm{C}$, por 60 minutos. Os soros foram diluídos na proporção de 1:200 em tampão de incubação (PBS; 0,25\% caseína; 0,05\% de tween 20) e distribuídos $100 \mu \mathrm{l} /$ cavidade, sendo levados à estufa a $37^{\circ} \mathrm{C}$, por 120 minutos. Após, a placa foi novamente lavada e um segundo anticorpo (Chicken IgG HRP - A30-107P - Bethyl ${ }^{\circledR}$ ), diluído na proporção de 1:20.000, foi distribuído em 100uL/cavidade e incubados em estufa por 60 minutos. 0 substrato utilizado para leitura da placa foi o TMB (Sinapse ${ }^{\circledR}$ ), seguindo-se a leitura após a interrupção da reação com a adição de ácido fosfórico 1M, em comprimento de onda de $450 \mathrm{~nm}$.

Os dados obtidos foram submetidos à análise de variância e as médias comparadas pelo teste $\mathrm{T}$, a $5 \%$ de probabilidade, utilizando o software estatístico SAS (Version 9.0, SAS Institute Inc., Cary, NC, EUA, 2002)

Quadro 1. Composição centesimal e calculada das dietas experimentais para codornas em postura alimentadas com diferentes níveis de extrato de orégano

\begin{tabular}{|c|c|c|c|c|c|}
\hline \multirow[t]{2}{*}{ Ingredientes } & \multicolumn{5}{|c|}{ Tratamentos } \\
\hline & Controle & $0,025 \%$ & $0,050 \%$ & $0,100 \%$ & $0,150 \%$ \\
\hline Milho grão, moído & 50,232 & 50,210 & 50,180 & 50,110 & 50,050 \\
\hline Farelo de soja - $45 \%$ & 36,575 & 36,581 & 36,587 & 36,600 & 36,610 \\
\hline Extrato de orégano & 0,000 & 0,025 & 0,050 & 0,100 & 0,150 \\
\hline Calcário calcítico & 5,360 & 5,360 & 5,360 & 5,360 & 5,360 \\
\hline Óleo de soja & 3,200 & 3,200 & 3,200 & 3,200 & 3,200 \\
\hline Sal comum & 0,400 & 0,400 & 0,400 & 0,400 & 0,400 \\
\hline DL-metionina - 99\% & 0,151 & 0,151 & 0,151 & 0,151 & 0,151 \\
\hline L-Lisina $\mathrm{HCl}$ - 79\% & 0,074 & 0,074 & 0,074 & 0,074 & 0,074 \\
\hline Supl. Mineral+vit. ${ }^{1}$ & 4,000 & 4,000 & 4,000 & 4,000 & 4,000 \\
\hline Antioxidante $^{2}$ & 0,010 & 0,010 & 0,010 & 0,010 & 0,010 \\
\hline TOTAL & 100,00 & 100,00 & 100,00 & 100,00 & 100,00 \\
\hline \multicolumn{6}{|l|}{ Composição calculada } \\
\hline EM (kcal/kg) & 2.850 & 2.850 & 2.850 & 2.850 & 2.850 \\
\hline Proteína Bruta (\%) & 22,00 & 22,00 & 22,00 & 22,00 & 22,00 \\
\hline Cálcio (\%) & 3,15 & 3,15 & 3,15 & 3,15 & 3,15 \\
\hline Fósforo disponível (\%) & 30 & 0,30 & 0,30 &, 30 & 0,30 \\
\hline Fósforo & 0,56 & 0,56 & 0,56 & ,56 & 0,56 \\
\hline Fibra Bruta (\%) & 3,42 & 3,42 & 3,42 & 42 & 3,42 \\
\hline Lisina digestível (\%) & 1,10 & 1,10 & 1,10 & 1,10 & 1,10 \\
\hline Lisina total (\%) & 1,21 & 1,21 & 1,21 & 1,21 & 1,21 \\
\hline Metionina digestível (\%) & 0,42 & 0,42 & 0,42 & 0,42 & 0,42 \\
\hline Metionina total (\%) & 0,52 & 0,52 & 0,52 & 0,52 & 0,52 \\
\hline Met+cist. digestível (\%) & 0,72 & 0,72 & 0,72 & 0,72 & 0,72 \\
\hline Met+cist. total (\%) & 0,84 & 0,84 & 0,84 & 0,84 & 0,84 \\
\hline Sódio (\%) & 0,20 & 0,20 & 0,20 & 0,20 & 0,20 \\
\hline Cloro (\%) & 0,26 & 0,26 & 0,26 & 0,26 & 0,26 \\
\hline Potássio (\%) & 0,79 & 0,79 & 0,79 & 0,79 & 0,79 \\
\hline $\mathrm{BED}(\mathrm{mEq} / \mathrm{kg})^{3}$ & 213,43 & 213,43 & 213,43 & 213,43 & 213,43 \\
\hline
\end{tabular}

Composição do suplemento mineral e vitamínico (kg do produto): Vitamina A (min)12,000.00 UI/kg; vitamina $B_{1}(\mathrm{~min}) 2,40 \mathrm{mg} / \mathrm{kg}$; vitamina $B_{12}(\min ) 20,00 \mathrm{mcg} / \mathrm{kg}$; vitamina $B_{2}(\min ) 11,00 \mathrm{mg} / \mathrm{kg}$, vitamina $B_{6}$ (min) $4,00 \mathrm{mg} / \mathrm{kg}$; vitamina $\mathrm{D}_{3}(\mathrm{~min}) 2,400.00 \mathrm{UI} / \mathrm{kg}$ vitamina $\mathrm{E}(\mathrm{min})$ $24.000 \mathrm{UI} / \mathrm{kg}$; vitamina $\mathrm{K}_{3}(\mathrm{~min}) 3,00 \mathrm{mg} / \mathrm{kg}$; cobalto (min) $0,18 \mathrm{mg} / \mathrm{kg}$; cobre (min) $9,00 \mathrm{mg} / \mathrm{kg}$; ferro (min) $45,00 \mathrm{mg} / \mathrm{kg}$; iodo (min) $0,90 \mathrm{mg} /$ $\mathrm{kg}$; manganês $(\mathrm{min}) 54,00 \mathrm{mg} / \mathrm{kg}$ selênio $(\mathrm{min}) 0,32 \mathrm{mg} / \mathrm{kg}$; sódio (min) $1,800.00 \mathrm{mg} / \mathrm{kg}$; zinco ( $\mathrm{min}$ ) 45,00mg/kg; acido fólico (min) 2,00 mg/kg; acido pantotenico (min) $19,95 \mathrm{mg} / \mathrm{kg}$; biotina (min) 0,14mg/ $\mathrm{kg}$; niacina $(\mathrm{min}) 48,00 \mathrm{mg} / \mathrm{kg}$; colina $(\mathrm{min}) 180,00 \mathrm{mg} / \mathrm{kg}$. BHT = Butil Hidróxi Tolueno. Balanço Eletrolítico da Dieta, segundo Mongin (1981) No. de Mongin $=\left[\left(\% \mathrm{Na}^{*} 10.000 / 22,990\right)+\left(\% \mathrm{~K}^{*} 10.000 / 39,102\right)\right]-(\%$ $\left.\mathrm{Cl}^{*} 10.000 / 35,453\right)$. 


\section{RESULTADOS}

Os resultados médios das características de desempenho produtivo estão apresentados no Quadro 2. Não houve interação $(p>0,05)$ dos fatores avaliados para as características analisadas. No entanto, aves submetidas ao desafio com cepas de Eschcerichia coli apresentaram piores desempenhos em relação aos grupos não desafiados, para todos os níveis de suplementação com o extrato de orégano (EO) nas rações, exceto para a porcentagem de postura, onde aves ali- -se amareladas nas primeiras horas de avaliação PI, perdendo essa pigmentação com o passar do tempo até o final do período avaliado (168 horas PI). Não houve presença de hemorragia na lesão peitoral em qualquer ave dos grupos desafiados.

Os valores médios da titulação de anticorpos específicos, contra o antígeno de E. coli, em soros de codornas estão apresentados no Quadro 4. Não foi observado $(p>0,05)$ efeito do extrato de orégano sobre a titulação de anticorpos

Quadro 2. Médias* das características de desempenho produtivo de codornas japonesas, alimentadas com dietas enriquecidas com extrato de orégano (E0) e desafiadas com Escherichia coli

\begin{tabular}{|c|c|c|c|c|c|}
\hline EO & E. coli & Postura & Consumo & CA & Viabilidade \\
\hline \multirow[t]{2}{*}{0,000} & Sem & $82,66 \pm 7,12^{\mathrm{a}}$ & $31,06 \pm 1,26^{b}$ & $0,458 \pm 0,050^{b}$ & $86,90 \pm 8,73^{a}$ \\
\hline & Com & $72,64 \pm 10,06^{b}$ & $71,67 \pm 5,67^{a}$ & $1,100 \pm 0,215^{\mathrm{a}}$ & $16,67 \pm 10,11^{b}$ \\
\hline \multirow[t]{2}{*}{0,025} & Sem & $82,16 \pm 10,40^{a}$ & $31,98 \pm 3,15^{b}$ & $0,477 \pm 0,075^{b}$ & $88,10 \pm 15,87^{a}$ \\
\hline & Com & $74,84 \pm 15,56^{b}$ & $69,97 \pm 4,83^{a}$ & $1,178 \pm 0,266^{a}$ & $13,49 \pm 7,50^{b}$ \\
\hline \multirow[t]{2}{*}{0,050} & Sem & $86,12 \pm 6,95^{\mathrm{a}}$ & $31,79 \pm 2,85^{b}$ & $0,450 \pm 0,057^{b}$ & $90,08 \pm 9,92^{\mathrm{a}}$ \\
\hline & Com & $78,73 \pm 11,35^{b}$ & $67,22 \pm 8,07^{a}$ & $1,121 \pm 0,255^{\mathrm{a}}$ & $13,89 \pm 8,20^{b}$ \\
\hline \multirow[t]{2}{*}{0,100} & Sem & $81,36 \pm 10,34^{\mathrm{a}}$ & $31,71 \pm 2,01^{b}$ & $0,477 \pm 0,059^{b}$ & $92,06 \pm 10,58^{a}$ \\
\hline & Com & $72,96 \pm 11,82^{b}$ & $65,90 \pm 9,37^{a}$ & $1,165 \pm 0,227^{a}$ & $32,54 \pm 12,17^{b}$ \\
\hline \multirow[t]{2}{*}{0,150} & Sem & $82,58 \pm 10,83^{a}$ & $28,53 \pm 1,32^{b}$ & $0,436 \pm 0,075^{b}$ & $89,68 \pm 6,88^{a}$ \\
\hline & Com & $85,34 \pm 11,79^{a}$ & $71,29 \pm 6,92^{\mathrm{a}}$ & $1,023 \pm 0,159^{a}$ & $15,48 \pm 8,32^{b}$ \\
\hline \multicolumn{6}{|l|}{ Valor P } \\
\hline EO & & ns & ns & ns & ns \\
\hline E. coli & & 0,0187 & 0,0001 & 0,0001 & 0,0001 \\
\hline $\mathrm{EO}^{*}$ E. coli & & ns & ns & ns & ns \\
\hline $\mathrm{CV}(\%)$ & & 16,00 & 13,57 & 17,48 & 21,65 \\
\hline
\end{tabular}

*Média \pm Desvio Padrão; Valores médios seguidos pela mesma letra, minúscula na coluna, não diferem entre si pelo teste $\mathrm{T}(\mathrm{p} \geq 0,05) ; \mathrm{CV}=$ Coeficiente de variação; $\mathrm{CRD}=$ consumo de ração diário (grama/ave/dia); $\mathrm{CA}(\mathrm{kKg} / \mathrm{Dz})=$ conversão alimentar (kg de ração/dúzia de ovo).

Quadro 3. Médias* das lesões macroscópicas peitorais ( $\mathrm{mm})$ em codornas japonesas, alimentadas com dietas enriquecidas com extrato de orégano (EO) e desafiadas com cepas de Escherichia coli (EC)

\begin{tabular}{ccccccc}
\hline \multirow{2}{*}{$\begin{array}{c}\text { Período de } \\
\text { avaliação (hs) }\end{array}$} & Controle & Controle (EC $\left.{ }^{* *}\right)$ & $0,025 \%\left(\mathrm{EC}^{* *}\right)$ & $0,050 \%\left(\mathrm{EC}^{* *}\right)$ & $0,100 \%\left(\mathrm{EC}^{* *}\right)$ & $0,150 \%\left(\mathrm{EC}^{* *}\right)$ \\
\cline { 2 - 6 } & $0,0 \pm 0,0^{\mathrm{Ba}}$ & $19,19 \pm 5,86^{\mathrm{Aab}}$ & $21,51 \pm 7,04^{\mathrm{Aab}}$ & $23,37 \pm 6,48^{\mathrm{Aa}}$ & $22,41 \pm 4,94^{\mathrm{Aa}}$ & $19,42 \pm 4,42^{\mathrm{Aa}}$ \\
\hline 24 & $0,0 \pm 0,0^{\mathrm{Ba}}$ & $23,78 \pm 4,10^{\mathrm{Aa}}$ & $25,73 \pm 5,77^{\mathrm{Aa}}$ & $25,41 \pm 4,55^{\mathrm{Aa}}$ & $23,75 \pm 3,92^{\mathrm{Aa}}$ & $21,28 \pm 2,89^{\mathrm{Aa}}$ \\
72 & $0,0 \pm 0,0^{\mathrm{Ba}}$ & $19,98 \pm 5,55^{\mathrm{Aab}}$ & $23,39 \pm 4,90^{\mathrm{Aa}}$ & $23,65 \pm 4,09^{\mathrm{Aa}}$ & $23,06 \pm 3,45^{\mathrm{Aa}}$ & $18,88 \pm 3,16^{\mathrm{Aa}}$ \\
96 & $0,0 \pm 0,0^{\mathrm{Ba}}$ & $14,66 \pm 3,84^{\mathrm{Abc}}$ & $16,37 \pm 4,12^{\mathrm{Ab}}$ & $15,92 \pm 4,82^{\mathrm{Ab}}$ & $15,26 \pm 3,20^{\mathrm{Ab}}$ & $14,11 \pm 4,32^{\mathrm{Ab}}$ \\
168 & $0,0 \pm 0,0^{\mathrm{Ba}}$ & $9,19 \pm 5,25^{\mathrm{Ac}}$ & $13,62 \pm 3,25^{\mathrm{Ab}}$ & $13,39 \pm 4,94^{\mathrm{Ab}}$ & $11,84 \pm 1,92^{\mathrm{Ab}}$ & $9,52 \pm 5,38^{\mathrm{Ab}}$
\end{tabular}

* Média \pm Desvio Padrão; **Aves dos tratamentos desafiados com E. coli. Valores médios seguidos pela mesma letra, maiúscula na linha e minúscula na coluna, não diferem entre si pelo teste $\mathrm{t}(\mathrm{p} \geq 0,05)$.

mentadas com $0,150 \%$ de EO e desafiadas com E. coli, não diferiram do grupo sem desafio.

Para as características das lesões macroscópicas peitorais (Quadro 3), foram observadas lesões apenas nas aves dos tratamentos que sofreram desafio com E. coli, independentemente do nível de extrato de orégano avaliado. No entanto, de acordo com o tamanho, cor e presença ou não de hemorragia, as lesões foram caracterizadas como grau leve, de acordo com Peighambari et al. (1995). Não houve a contaminação por outras bactérias de acordo com a análise bacteriológica realizadas no interior das lesões.

De acordo com as horas de avaliação pós-inoculação (PI), pode ser observado um mesmo comportamento para todos os grupos desafiados com E. coli, onde houve um aumento do tamanho das lesões até aproximadamente 72 horas PI, apresentando após esse período, um decréscimo no tamanho. Em relação à coloração, as lesões apresentaram-
Quadro 4. Valores médios ${ }^{1}$ das absorbâncias do teste ELISA em soro de codornas, contra o antígeno de Escherichia coli, alimentadas com dietas enriquecidas com extrato de orégano (EO)

\begin{tabular}{lcccc}
\hline E0 & E. coli & Abs1 & Abs2 & Abs3 \\
\hline 0,00 & sem & $0,304 \pm 0,072^{\mathrm{Bb}}$ & $0,407 \pm 0,151^{\mathrm{Ab}}$ & $0,476 \pm 0,097^{\mathrm{Ab}}$ \\
0,025 & sem & $0,364 \pm 0,097^{\mathrm{Bb}}$ & $0,414 \pm 0,115^{\mathrm{Ab}}$ & $0,560 \pm 0,193^{\mathrm{Ab}}$ \\
0,050 & sem & $0,330 \pm 0,119^{\mathrm{Bb}}$ & $0,485 \pm 0,104^{\mathrm{Ab}}$ & $0,585 \pm 0,216^{\mathrm{Ab}}$ \\
0,100 & sem & $0,284 \pm 0,063^{\mathrm{Bb}}$ & $0,429 \pm 0,129^{\mathrm{Ab}}$ & $0,525 \pm 0,139^{\mathrm{Ab}}$ \\
0,150 & sem & $0,385 \pm 0,171^{\mathrm{Bb}}$ & $0,501 \pm 0,229^{\mathrm{Ab}}$ & $0,565 \pm 0,162^{\mathrm{Ab}}$ \\
0,00 & com & $0,421 \pm 0,133^{\mathrm{Ba}}$ & $0,544 \pm 0,118^{\mathrm{Aa}}$ & $0,650 \pm 0,197^{\mathrm{Aa}}$ \\
0,025 & com & $0,455 \pm 0,179^{\mathrm{Ba}}$ & $0,605 \pm 0,137^{\mathrm{Aa}}$ & $0,743 \pm 0,097^{\mathrm{Aa}}$ \\
0,050 & com & $0,402 \pm 0,138^{\mathrm{Ba}}$ & $0,701 \pm 0,307^{\mathrm{Aa}}$ & $0,740 \pm 0,215^{\mathrm{Aa}}$ \\
0,100 & com & $0,540 \pm 0,184^{\mathrm{Ba}}$ & $0,704 \pm 0,220^{\mathrm{Aa}}$ & $0,759 \pm 0,239^{\mathrm{Aa}}$ \\
0,150 & com & $0,481 \pm 0,141^{\mathrm{Ba}}$ & $0,623 \pm 0,223^{\mathrm{Aa}}$ & $0,682 \pm 0,288^{\mathrm{Aa}}$
\end{tabular}

${ }^{1}$ Média \pm Desvio Padrão; ${ }^{*}$ Valores médios seguidos pela mesma letra, maiúscula na linha e minúscula na coluna, não diferem entre si pelo teste $\mathrm{t}$ $(\mathrm{p} \geq 0,05) ; \mathrm{Abs} 1=10^{\circ}$ dia ( 5 dias após a $1^{\mathrm{a}}$ inoculação); $\mathrm{Abs} 2=35^{\circ}$ dia (30

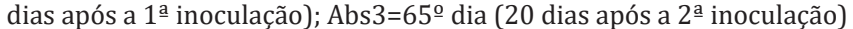
do período experimental. 
em codornas durante o período experimental. No entanto, os grupos desafiados com a E. coli, apresentaram um aumento de anticorpos frente ao antígeno, em relação aos grupos não desafiados. Essa característica foi avaliada em três diferentes períodos durante toda a avaliação experimental, a primeira amostragem foi no início do experimento (Abs1 - após cinco dias da 1a inoculação com E. coli), a segunda (Abs2 - após 30 dias da 1 a inoculação) e a terceira (Abs3 - após 20 dias da 2a inoculação), com o intuito de verificar o comportamento e a resistência imunológica das aves frente ao desafio.

\section{DISCUSSÃO}

No quadro de colibacilose podem ser observados sinais clínicos inespecíficos como: desuniformidade do lote, aumento da mortalidade, baixo consumo de ração e de ganho de peso. Em casos infecciosos, podem ser observadas lesões como: enterite, artrite, septicemia, aerossaculite, entre outros (Ferreira \& Knöbl 2009). Neste estudo, a queda no desempenho das aves foi evidente para os grupos desafiados com E. coli, onde foi observada uma grande mortalidade entre os grupos, aumento no índice de conversão alimentar e consequentemente, menor produtividade. A expectativa sobre o extrato de orégano, como fator antimicrobiano, não foi atendida nos níveis de suplementação avaliados.

Segundo Kindlein et al. (2007), o desencadeamento de uma colibacilose depende do nível de exposição do animal a bactéria e do grau de competência imunológica do mesmo, bem como variáveis de manejo, ambiente e alimentação. Esses mesmos autores, avaliaram a vitamina E e selênio em dietas de poedeiras comerciais que foram desafiadas com vacina contra E. coli. Aves suplementadas com vitamina E produziram maior quantidade de imunoglobulinas (IgY) em relação às não suplementadas. No entanto, níveis elevados desta vitamina podem apresentar efeito negativo ao sistema imune humoral. Do mesmo modo, Leshchinsky \& Klasing (2001) sugeriram que níveis entre 25 e $50 \mathrm{UI} / \mathrm{kg}$ apresentaram maiores efeitos imunomoduladores em frangos de corte.

De acordo com o comportamento observado para as lesões macroscópicas da celulite, aves dos grupos desafiados com E. coli, apresentaram aumento no tamanho das lesões até aproximadamente 72 horas PI e após esse período, um decréscimo no tamanho. Entretanto, ao realizar um corte, houve indícios de placas amareladas no subcutâneo. Essa reação foi devido à defesa imunológica celular (linfócitos $\mathrm{T}$ e macrófagos) que possuem a capacidade de fagocitar os invasores, causando assim uma reação inflamatória. As causas de alteração da resposta imune podem decorrer de vários fatores, como os nutricionais, genéticos, sanitário e manejo. Essas variações são, em parte, causadas por diferenças na intensidade do estressor, na duração do estímulo estressor e nas variações genéticas de linhagens e de indivíduos. Com isso, as variações dos resultados relacionados à imunidade da ave decorrem de vários fatores em conjunto, muitas vezes impossíveis de separação e controle (Fukayama et al. 2005).

Em estudos realizados com frangos de corte, Alves et al. (2007) realizaram uma avaliação epidemiológica em aves de um matadouro sob Inspeção Sanitária e observaram macroscopicamente lesões cutâneas localizadas na coxa, dorso e área cloacal em frangos, caracterizadas como sendo celulite, por apresentar um aumento na espessura da pele e coloração amarelo avermelhada, corroborando com achados por outros pesquisadores (Brito 2002, Silva \& Mota 2003, Andrade et al. 2006). Por outro lado, Vieira et al. (2006), observaram que seis das dez aves com lesões suspeitas de celulite não apresentaram alteração na coloração ou espessamento da pele, havendo apenas foco de ulceração. No entanto, pôde ser verificado que ao realizar um corte, havia no subcutâneo, a presença de placas amareladas, características da celulite, apesar da ausência de alterações macroscópicas na pele frequentemente descrita. Dessa forma, uma análise histopatológica torna-se uma ferramenta importante para a confirmação do diagnóstico, permitindo uma rápida diferenciação entre as demais lesões cutâneas.

O desafio com E. coli resultou em um aumento na titulação de anticorpos específicos nas codornas em todos os grupos desafiados, demonstrando assim uma forma de resistência do próprio organismo frente ao agente infeccioso, que provocou a quebra na homeostase do sistema imune, esta responsável pela manutenção da sanidade das aves (equilíbrio entre bactéria, hospedeiro e o meio ambiente). Normalmente, na maioria dos animais, a resposta a um segundo desafio é muito mais rápida e pode atingir níveis de anticorpos mais elevados. É uma resposta específica, já que pode ser induzida somente por um antígeno semelhante ao primeiro (Tizard 1985).

A bactéria acomete aves em todas as idades, porém a susceptibilidade das aves e a severidade da enfermidade são maiores em aves mais jovens, quando a microbiota normal ainda não está estabelecida, podendo ser encontrada em concentrações bem maiores que $10^{6} \mathrm{UFC} /$ grama de fezes. A colibacilose resulta da interação e alteração do equilíbrio entre bactéria, hospedeiro e o meio ambiente. As condições ambientais (alta concentração de amônia e deficiência na ventilação no galpão, temperaturas extremas) e de manejo (densidade elevada na criação e má desinfecção no galpão), contribuem para a ocorrência da doença, pois a bactéria é considerada um patógeno oportunista (Ferreira et al. 2009).

\section{CONCLUSÕES}

Os níveis de suplementação avaliados do extrato de orégano nas rações não se mostraram eficazes frente ao desafio de Escherichia coli sobre as características de desempenho produtivo das codornas na fase de postura.

As aves desafiadas com E. coli apresentaram maior resposta imune humoral e celular, em relação às não desafiadas, caracterizado pelo aumento no título de anticorpos específicos e pela reação celular da lesão macroscópica peitoral, em grau leve, independentemente dos níveis de extrato de orégano avaliados.

Agradecimentos.- Ao Conselho Nacional de Desenvolvimento Científico e Tecnológico (CNPq), pelo suporte financeiro disponibilizado. 


\section{REFERÊNCIAS}

Alves F.M.X., Pereira V.L.A., Nascimento E.R., Guimarães A.M.P., Almeida D.O. \& Torlelly R. 2007. Celulite associada às lesões na bolsa de Fabrício de frangos de corte ao abate, sob inspeção sanitária. Revta Bras. Ciênc. Vet. 14(1):23-27.

Andrade C.L., Ferreira G.B., Franco R.M., Nascimento E.R. \& Tortelly R. 2006. Alterações patológicas e identificação de Escherichia coli como agente causal da celulite aviária em frangos de corte inspecionados em matadouro de São Paulo. Revta Bras. Ciênc. Vet. 13(3):139-143.

Borges V.P. 2006. Principais lesões macro e microscópicas em frangos de corte condenados por caquexia em abatedouro: contribuição ao diagnóstico. Dissertação de Mestrado em Ciência Animal, Universidade Estadual Paulista, São Paulo, SP. 125p.

Bradford M.M. 1976. A rapid and sensitive method for the quantitation of microgram quantities of protein utilizing the principle of protein-dye binding. Anal. Biochem. 72:248-254.

Brito B.G. 2002. Celulite em frangos de corte causada por Escherichia coli. Semina, Ciênc. Agrárias 23(1):81-84.

Brito B.G., Gaziri L.C.J. \& Vidotto M.C. 2003. Virulence factors and clonal relationships among Escherichia coli strains isolated from broiler chickens with cellulitis. Infect. Immun. 71(7):4175-4177.

Catalan A.A.S., Gopinger E., Lopes D.C.N., Gonçalves F.M., Roll A.A.P., Xavier E.G., Avila V.S. \& Roll V.F.B. 2012. Aditivos fitogênicos na nutrição animal: Panax ginseng. Revta Port. Ciênc. Vet. 111:15-21.

Fallavena L.C.B. 2000. Enfermidades da pele e das penas, p.37-47. In: Berchieri Jr A. \& Macari M. (Eds), Doenças das Aves. FACTA, Campinas.

Ferreira A.J.P. \& Knöbl T. 2009. Colibacilose aviária, p.457-471. In: Berchieri Jr A., Silva E.N., Di Fábio J., Sest L. \& Zuanaze M.A. (Eds), Doenças das Aves, $2^{\mathrm{a}}$ ed. FACTA, Campinas.

Ferreira A.J.P., Revolledo L. \& Ferreira C.S.A. 2009. Colibacilose, p.67-74. In: Revolledo L. \& Ferreira A.J.P. (Eds), Patologia Aviária. Manole, Barueri.

Ferreira T.Z., Sesterhenn R. \& Kindlein L. 2012. Perdas econômicas das principais causas de condenações de carcaças de frangos de corte em matadouros-frigoríficos sob Inspeção Federal no Rio Grande do Sul, Brasil. Acta Scient. Vet. 40(1):1021-1026.
Fukayama E.H., Bertechini A.G., Geraldo A.G., Kato R.H. \& Murgas L.D.S. 2005. Extrato de orégano como aditivo em rações para frangos de corte. Revta Bras. Zootec. 34(6):2316-2326.

Kindlein G., Ribeiro A.M.L., Canal C.W. \& Vieira M.M. 2007. Feeding different levels of vitamin $\mathrm{E}$ and selenium has no effect on serum immunoglobulin Y (IgY) production by layers vaccinated against Escherichia coli and avian encephalomyelitis virus. Ciência Rural 37(5):1374-1379.

Leshchinsky T.V. \& Klasing K.C. 2001. Relationship between the level of dietary vitamin $\mathrm{E}$ and the immune response of broiler chickens. Poult. Sci. 80:1590-1599.

Marino M., Bersani C. \& Comi G. 2001. Impedance measurements to study the antimicrobial activity of essential oils from Lamiaceae and Compositae. Int. J. Food Microbiol. 67:187-195.

Pastore S.M., Oliveira W.P. \& Muniz J.C.L. 2012. Panorama da coturnicultura no Brasil. Revta Eletr. Nutritime 9(6):2041-2049.

Peighambari S.M., Vaillancourt J.P., Wilson R.A. \& Gyles C.L. 1995. Characteristics of Escherichia coli isolates from avian cellulitis. Avian Dis. 39:116-124.

Rostagno H.S., Albino L.F.T., Donzele J.L., Gomes P.C., Oliveira R.F., Lopes D.C., Ferreira A.S., Barreto S.L.T. \& Euclides R.F. 2011. Tabelas brasileiras para aves e suínos: composição de alimentos e exigências nutricionais. 3a ed. Departamento de Zootecnia, UFV, Viçosa, MG. 252p.

SAS. 2002. Statistical Analysis System. SAS user's guide: Statistic. SAS Institute Inc., Cary, NC.

Silva J.H.V. \& Costa F.G.P. 2009. Tabela para codornas japonesas e européias. $2^{a}$ ed., Funep, Jaboticabal, SP. 110p.

Silva E.N. \& Mota M.P. 2003. Celulite em Frangos de Corte. Disponível em <http://www.fatec.com.br/trabtec/celulit_em_frangos_de_ corte.htm> Acessado em 27 nov. 2003.

Tizard I. 1985. Introdução à Imunologia Veterinária. $2^{\text {a }}$ edição. Roca, São Paulo, SP. 321p.

Vieira T., Franco R.M., Magalhães H., Praxedes C.I.S. \& Tortelly R. 2006. Celulite em frangos de corte abatidos sob inspeção sanitária: aspectos anatomopatológicos associados ao isolamento de Escherichia coli. Revta Bras. Ciênc. Vet. 13(3):174-177. 